\title{
Independent and Synergistic Activity of Synthetic Peptides Against Thiabendazole-Resistant Fusarium sambucinum
}

\author{
C. F. Gonzalez, E. M. Provin, L. Zhu, and D. J. Ebbole
}

First, second, and fourth authors: Department of Plant Pathology and Microbiology, Texas A\&M University, College Station 77843; and third author: Department of Epidemiology and Biostatistics, School of Rural Public Health, Texas A\&M University System Health Science Center, College Station 77802.

Accepted for publication 9 May 2002.

\begin{abstract}
Gonzalez, C. F., Provin, E. M., Zhu, L., and Ebbole, D. J. 2002. Independent and synergistic activity of synthetic peptides against thiabendazoleresistant Fusarium sambucinum. Phytopathology 92:917-924.

Two heptapeptides with broad antifungal activity were identified and assessed for their ability to act synergistically with thiabendazole. The hexapeptide 66-10 was the progenitor of the heptapeptides and exhibited minimal inhibitory concentrations (MICs) of 9.3 to $9.8 \mu \mathrm{g} / \mathrm{ml}$ for thiabendazole (TBZ) resistant Fusarium sambucinum strains (MIC of 186 to $312 \mu \mathrm{g} / \mathrm{ml}$ ). Heptapeptide derivatives 77-3 and 77-12 exhibited MICs between 3.8 and $7.5 \mu \mathrm{g} / \mathrm{ml}$ against the same strains. Incubation of conidia or

mycelia with the peptide 77-3 showed that treated fungal structures were stained by the membrane impermeant dye SYTOX Green indicating disruption of membranes. Conidia incubated with peptide $77-3$ at $10 \mu \mathrm{g} / \mathrm{ml}$ showed a $91 \pm 3.6 \%$ reduction in viability in $15 \mathrm{~min}$. A checkerboard method was used to test the peptides and TBZ individually and in combination to determine potential synergistic activity. The results indicate that small peptides can act synergistically with TBZ against TBZ-resistant $F$. sambucinum.

Additional keywords: antimicrobial peptide, F. sulphureum, Gibberella pulicaris.
\end{abstract}

Fusarium sambucinum Fuckel (telomorph Gibberella pulicaris (Fries) Sacc.) causes dry rot of potato (Solanum tuberosum L.). In North America, where the primary method of preservation of potatoes is cold storage, $F$. sambucinum is the predominant cause of potato dry rot (30). Infection of the tubers occurs when wounds inflicted during harvest or storage are colonized by the pathogen. Control of dry rot is normally achieved by preventing tuber damage, promoting suberization, and applying fungicides (30).

Since the early 1970s, thiabendazole (TBZ) has been extensively used to control dry rot $(14,26)$ of seed and stored potatoes. However, resistance to TBZ has been reported in strains of $F u$ sarium sambucinum from the United States, Canada, and Europe $(13,14,21,22)$. In a study to determine the population structure and genetic basis of TBZ resistance in $F$. sambucinum, Desjardins et al. (14) reported that TBZ-resistant strains were vegetatively compatible with TBZ-sensitive strains. Their genetic analysis further indicted that TBZ resistance was inherited as a single gene or as closely linked genes, and that resistance loci of independently isolated field strains were allelic. Importantly, their results also indicated that TBZ-resistant strains were competitive with sensitive strains and, therefore, had the potential to spread and persist in fields. Hanson et al. (21) found $80 \%$ of the TBZ resistant $\mathrm{Fu}$ sarium species associated with dry rot of potato in the northeastern United States were $F$. sambucinum.

The resistance and potential for transfer of TBZ resistance in $F$. sambucinum, therefore, limits the effectiveness of the fungicide in controlling dry rot of potato, and alternative strategies are needed to replace or extend the use of the fungicide. Synthetic combinatorial libraries allow screening of large numbers of chemically distinct compounds in a high throughput approach, and have brought a new dimension to the design and identification of novel bio-

Corresponding author: C. F. Gonzalez; E-mail address: cf-gonzalez@tamu.edu

Publication no. P-2002-0620-01R

(C) 2002 The American Phytopathological Society logically active compounds (9). The potential of fungicides or bioactive compounds, such as peptides, to act in combination provides an approach to increasing in vivo activity of fungicides, broadening their activity, and possibly preventing or delaying the emergence of resistance (19). Thiabendazole resistant $F$. sambucinum provide a model system in which to test the efficacy of bioactive peptides in extending the usefulness of fungicides, such as TBZ. The purpose of this study was to evaluate the potential for synthetic hexa- and hepta-peptides to act individually or in a synergistic manner with TBZ against TBZ-resistant $F$. sambucinum strains.

\section{MATERIALS AND METHODS}

Fungal strains and media used in the study. Strains of $F$. sambucinum were obtained from the Fusarium Research Center (The Pennsylvania State University, University Park). TBZ-resistant strains R9257, R9260, R9261, and R9263 and TBZ-sensitive strains R9149 and R9262 used in this study were isolated from dry-rotted potato tubers (14). All cultures were grown on carnation leaf agar (17) and reisolated from a single conidium. Sensitivity or resistance of the isolates to TBZ was confirmed using V8 juice agar amended with TBZ at $0,5,10,25$, or $50 \mu \mathrm{g} / \mathrm{ml}$ (Aldrich, Milwaukee, WI). In three independent experiments, radial growth from the center of the petri plate $(100 \times 15 \mathrm{~mm})$ was measured after 5 days at $25^{\circ} \mathrm{C}$ for triplicate plates inoculated with a 3-mmdiameter plug cut from the growing margin of a 6-day-old colony. Potato dextrose broth (PDB) was used as the medium in microtiter plates to determine the individual or combined growth inhibitory activity of the tested compounds.

Growth and storage conditions for stock cultures and production of inoculum for bioassays. All fungal cultures were grown at $25^{\circ} \mathrm{C}$ and routinely maintained on V8 juice agar that was amended with TBZ $(50 \mu \mathrm{g} / \mathrm{ml})$ for resistant strains. For long-term storage of each isolate, 2 to $5 \times 10^{7}$ conidia per $\mathrm{ml}$ were suspended in PDB containing 20\% sterile glycerol and 1-ml aliquots were 
stored at $-80^{\circ} \mathrm{C}$. An aliquot of each conidial suspension was streaked to tryptone nutrient agar $(31)$ and incubated at $25^{\circ} \mathrm{C}$ for $48 \mathrm{~h}$ to verify that the suspensions were bacteria-free. To obtain inoculum for each experiment, a conidial suspension from each frozen stock was diluted in PDB and $10^{3}$ conidia were spread on the V8 juice agar with or without TBZ as appropriate, and allowed to grow for 5 days at $25^{\circ} \mathrm{C}$. Conidial suspensions were prepared by adding $10 \mathrm{ml}$ of PDB over the surface of each culture, agitating with a sterile glass rod, and filtering twice through three layers of sterile cheesecloth. The conidial suspensions were adjusted to a concentration of $3 \times 10^{7}$ conidia per $\mathrm{ml}$ and diluted to inoculate 96-well microtiter bioassay plates to a final concentration of $3 \times$ $10^{4}$ conidia per well.

Antimicrobial peptides and bioassay. The D-amino acid peptides used in the study were purchased from Quality Controlled Biochemicals, Inc., Hopkinton, MA, and synthesized by fmoc solid-phase peptide synthesis using a peptide synthesizer. All peptides were confirmed to be more than $95 \%$ pure by analytical high-performance liquid chromatography. Lyophilized peptides were reconstituted in sterile double distilled-deionized water. The hexapeptide FRLKFH-NH $\mathrm{NH}_{2}, 66-10$, was developed in the study by Reed et al. (34) and the heptapeptides FRLKFHF-NH $\mathrm{NH}_{2}$ and

TABLE 1. Minimal inhibitory concentrations of thiabendazole (TBZ) and synthetic peptides $66-10,77-3$, or 77-12 for TBZ-resistant and -sensitive strains of Fusarium sambucinum ${ }^{\text {a }}$

\begin{tabular}{lrrcc}
\hline Strain $^{\mathrm{b}}$ & ${\text { TBZ }(\mu \mathrm{g} / \mathrm{ml})^{\mathrm{c}}}^{\mathrm{c}}$ & $66-10(\mu \mathrm{g} / \mathrm{ml})^{\mathrm{d}}$ & $77-3(\mu \mathrm{g} / \mathrm{ml})^{\mathrm{e}}$ & $77-12(\mu \mathrm{g} / \mathrm{ml})^{\mathrm{f}}$ \\
\hline R9149(S) & $4.7 \pm 0.2$ & $7.8 \pm 0.3$ & $3.8 \pm 0.0$ & $3.8 \pm 0.0$ \\
R9257(R) & $186.0 \pm 2.0$ & $9.3 \pm 0.1$ & $4.0 \pm 0.0$ & $3.9 \pm 0.0$ \\
R9260(R) & $172.0 \pm 1.0$ & $9.9 \pm 0.1$ & $4.0 \pm 0.0$ & $3.7 \pm 0.0$ \\
R9261(R) & $241.0 \pm 5.0$ & $9.9 \pm 0.1$ & $3.8 \pm 0.2$ & $6.2 \pm 0.2$ \\
R9262(S) & $4.8 \pm 0.1$ & $10.2 \pm 0.1$ & $3.9 \pm 0.0$ & $7.7 \pm 0.1$ \\
R9263(R) & $312.0 \pm 2.0$ & $9.8 \pm 0.2$ & $3.9 \pm 0.0$ & $7.5 \pm 0.1$ \\
\hline
\end{tabular}

${ }^{\mathrm{a}}$ Minimal inhibitory concentrations are the lowest concentrations of the test compounds at which there was no detectable growth \pm the standard deviation for three independent experiments in triplicate.

${ }^{\mathrm{b}} \mathrm{S}$ or $\mathrm{R}$ notation in parenthesis refers to TBZ-resistant or -sensitive strains, respectively.

${ }^{\mathrm{c}}$ For TBZ, $0.20 \mu \mathrm{g} / \mathrm{ml}=1 \mu \mathrm{M}$.

${ }^{\mathrm{d}}$ For peptide $66-10(0.85 \mu \mathrm{g} / \mathrm{ml}=1 \mu \mathrm{M})$.

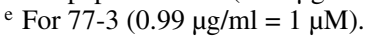

${ }^{\mathrm{f}}$ For $77-12(0.96 \mu \mathrm{g} / \mathrm{ml}=1 \mu \mathrm{M})$.
FRLKFHI-NH $\mathrm{N}_{2}$ (77-3 and 77-12, respectively) were developed in this study. The two heptapeptides were selected for this study from a pool of 20 individual peptides that were one amino acid extensions of peptide 66-10 each having one of each of the 20 amino acids in position seven. Heptapeptides 77-3 and 77-12 were selected because of their high level of antifungal activity. The minimal inhibitory concentration (MIC) of TBZ and the individual peptides was determined using a 96-well microtiter plate bioassay. Fifty microliters of $1 \times$ PDB was added to all wells of sterile, disposable, flat bottom, polystyrene, 96-well (with lid) microtiter plates (Corning Glass Works, Scientific Products Division, Corning, NY) except A1-A3 and B1-H1. Wells A1-A3 received $100 \mu \mathrm{l}$ of $1 \times$ PDB to function as media control wells. Wells B1-H1 received $50 \mu$ of $2 \times$ PDB. Wells A4-A12 were designated growth controls and received no TBZ or peptide. Aqueous solutions of either TBZ or peptide were added to each of wells B1-H1 in 50- $\mu 1$ aliquots and a twofold serial dilution was carried out across each row with a starting concentration of TBZ at 625 or $250 \mu \mathrm{g} / \mathrm{ml}$ for the peptides with an ending concentration of either 0.30 or $0.12 \mu \mathrm{g} / \mathrm{ml}$, respectively. Once the individual peptide compounds had been diluted across each row, the microtiter plate (excluding wells A1-A3) was overlaid with $50 \mu \mathrm{l}$ of the selected fungal inoculum. The inoculum was prepared as described earlier. Absorbance readings $(595 \mathrm{~nm})$ were taken at $0,24,48$, and $72 \mathrm{~h}$. For TBZ or peptides, the data was expressed as a MIC, where the MIC was defined as the lowest concentration of the test peptide at which there was no growth. To obtain the MIC, absorbance readings from the final time interval were used to calculate the percent inhibition of growth. For all microtiter plates, absorbance values of 9 control wells (A4-A12) were averaged. The average absorbance value obtained for wells A4-A12 was individually divided into the absorbance values obtained for the dilution series of TBZ or peptide. Each value was subtracted from 100 to acquire the percent inhibition. By using percent inhibition as $x$ values and TBZ or peptide concentration as $y$ values, linear regression analysis was performed to obtain an MIC value. The MIC was expressed as the mean of three replicates \pm the standard deviation of three independent experiments.

A two-dimensional checkerboard microdilution technique was used to characterize interactions between TBZ and the peptides (15). This allowed for the testing of TBZ and the individual peptides alone and in combination in a serial dilution series. Three

TABLE 2. Individual and synergistic activity of peptides and/or thiabendazole (TBZ) against TBZ-resistant Fusarium sambucinum strain R9263

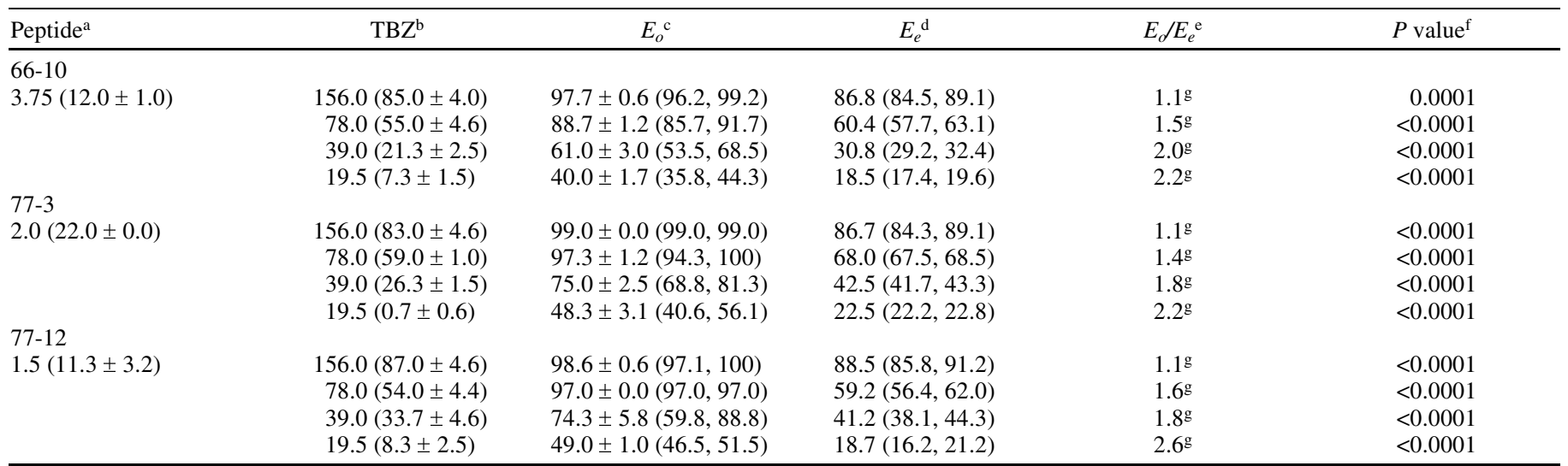

${ }^{a}$ Concentration $(\mu \mathrm{g} / \mathrm{ml})$ of designated peptide; number in parenthesis is the average percent inhibition of growth at the given concentration \pm the standard deviation (SD) for three independent experiments in triplicate.

${ }^{\mathrm{b}}$ Concentration $(\mu \mathrm{g} / \mathrm{ml})$ of TBZ; number in parenthesis is the average percent inhibition of growth at the given concentration \pm the SD for three independent experiments in triplicate.

${ }^{\mathrm{c}} E_{o}$ is the average observed combined inhibition of growth by the combination of peptide and TBZ at concentrations listed in columns one and two, respectively, \pm the SD for three independent experiments in triplicate; number in parenthesis are the calculated lower and upper limits for $95 \%$ confidence intervals (CIs).

${ }^{\mathrm{d}} E_{e}$ is the expected effect (percent inhibition) for an additive, non-synergistic effect; numbers in parenthesis are the calculated lower and upper limits for $95 \%$ CIs.

${ }^{\mathrm{e}} E_{o} / E_{e}>1$ and the $95 \%$ CIs for $E_{e}$ and $E_{o}$ do not overlap, then there is synergism.

f Calculated $P$ value.

${ }^{\mathrm{g}}$ Synergistic interactions meeting both statistical criteria. 
independent experiments in triplicate were performed for each of the isolates and TBZ-peptide combination. Inocula, TBZ, and peptides were prepared as for MIC testing with single compounds. For all experiments, the TBZ concentration ranged from a 312 to $4.9 \mu \mathrm{g} / \mathrm{ml}$ in a twofold dilution series in combination with a given range for the individual peptide in a twofold dilution series. The starting peptide concentration in a twofold dilution series varied with the individual peptide and strain based on the MIC. For strain R9263 the twofold dilution series of peptides tested with the TBZ series was from 15.0 to $0.23 \mu \mathrm{g} / \mathrm{ml}, 8$ to $0.13 \mu \mathrm{g} / \mathrm{ml}$, and 12 to $0.19 \mu \mathrm{g} / \mathrm{ml}$ for peptides 66-10, 77-3, and 77-12, respectively. For the same respective peptides, the twofold dilution series for strain R9261 was from 20 to $0.31 \mu \mathrm{g} / \mathrm{ml}, 8$ to $0.13 \mu \mathrm{g} / \mathrm{ml}$, and 12 to $0.19 \mu \mathrm{g} / \mathrm{ml}$, and for strain R9257 from 18 to $0.28 \mu \mathrm{g} / \mathrm{ml}, 8$ to $0.13 \mu \mathrm{g} / \mathrm{ml}$, and 8 to $0.13 \mu \mathrm{g} / \mathrm{ml}$. For strain R9260, the twofold dilution series of peptides was from 15.0 to $0.23 \mu \mathrm{g} / \mathrm{ml}, 8$ to $0.13 \mu \mathrm{g} / \mathrm{ml}$, and 8 to $0.13 \mu \mathrm{g} / \mathrm{ml}$ for peptides $66-10,77-3$, and 77 12 , respectively. Peptide synergistic activity testing used peptide concentrations between $\mathrm{IC}_{10}$ to $\mathrm{IC}_{30}$ for TBZ-resistant strains. At concentrations higher than $\mathrm{IC}_{30}$, the high growth inhibitory effects of the peptides may obscure detection of potential synergy. Absorbance readings $(595 \mathrm{~nm})$ were taken at $0,24,48$, and $72 \mathrm{~h}$ to determine the percent inhibition of growth by the individual or combined compounds. An absorbance versus dry weight correlation was resolved for each of the fungal isolates and shown to be linear using the protocol previously described (34). Briefly, all microtiter plates were inoculated as described earlier and incubated without shaking. At each time interval, the contents of 22 wells were collected and combined to form one sample. The sample was vacuum filtered through a preweighed, $0.45-\mu \mathrm{m}$, Millipore glass filter (Millipore Corp., Bedford, CT). The filter was dried at 15 torr, in a $70^{\circ} \mathrm{C}$ Thelco vacuum oven (Precision Scientific Co., Chicago, IL) to constant weight. The dried filters were allowed to come to room temperature in a vacuum desiccator. The tared weight of the filter was subtracted from the samplefilter weight to determine mycelial mass dry weight. At each time interval, the dry weight was calculated as mg per well. Absorbance readings, for each of the 22 wells collected at each time interval were averaged.

Analysis of data. Initial testing of TBZ and peptides 66-10, 773 , and 77-12 was accomplished to determine the MIC for each strain as described in the previous section. The MIC data was expressed as the mean of three replicates \pm the standard deviation of three independent experiments. The relative level of synergism was determined for each peptide and TBZ combination by applying Abbott's formula (1): $E_{e}=X+Y-X Y / 100$, where $E_{e}$ is the expected effect for an additive, non-synergistic effect, and $X$ and $Y$ are the percentages of inhibition relative to each compound used alone. The observed combined inhibition of growth $\left(E_{o}\right)$ is the average of three independent experiments in triplicate \pm standard deviation. Using a two-sample $t$ test to test the hypothesis that $E_{o}=E_{e}$, we calculated the $P$ value for each concentration of TBZ and peptide. If $E_{o} / E_{e}>1$ and $P<0.05$, the hypothesis for additivity is rejected and synergy is supported to a $95 \%$ confidence level (33). In addition, we used a conservative statistical approach for further analysis of the data. The $95 \%$ confidence interval for observed combined inhibition of growth $\left(E_{o}\right)$ was calculated as the average $E_{o} \pm 4.3 \times$ the standard deviation/square root of $n$, under the assumption that the mean $E_{o}$ has a student $t$ distribution with degree of freedom $=n-1=2$, since $n=3$ (3 independent experiments); 4.3 is the cutoff point for the student $t$ distribution that yields a $95 \%$ confidence level. The $95 \%$ confidence interval for expected combined inhibition $\left(E_{e}\right)$ was calculated as average $E_{e} \pm 2.3 \times$ the standard deviation/square root of $n$, under the assumption that the mean $E_{e}$ has a student $t$ distribution with degree of freedom $=n-1=8$, since $n=9$ (number of combinations of TBZ and peptide); 2.3 is the cutoff point for student $t$ distribution that yields a $95 \%$ confidence level. If $E_{o} / E_{e}>1$ and the $95 \%$ confidence intervals for $E_{e}$ and $E_{o}$ do not overlap, it is interpreted as a synergistic interaction between the two compounds (33). In this study, we reported synergistic interactions only if both statistical criteria were met.

Determination of potential target site for peptide activity. Conidia or hyphae of germinated conidia of F. sambucinum strain R9260 were used to determine the potential target of peptide 77-3. All strains were determined to be equally sensitive to the peptide and showed identical fluorescent staining when treated with the peptide followed by staining with SYTOX Green. The fluorescent dye SYTOX Green, a membrane impermeant nucleic acid stain (Molecular Probes, Inc., Eugene, OR) was used in the study at a final concentration of $1 \mathrm{nM}$ as described by Reed et al. (34). A time course study using $F$. sambucinum conidia, and SYTOX Green was used to resolve the exposure time necessary for peptide 77-3 to compromise fungal membranes. A series of microfuge

TABLE 3. Individual and synergistic activity of peptides and/or thiabendazole (TBZ) against TBZ-resistant Fusarium sambucinum strain R9261

\begin{tabular}{|c|c|c|c|c|c|}
\hline Peptide $^{a}$ & $\mathrm{TBZ}^{\mathrm{b}}$ & $E_{o}{ }^{\mathrm{c}}$ & $E_{e}^{\mathrm{d}}$ & $E_{o} / E_{e}^{\mathrm{e}}$ & $P$ value $^{\mathrm{f}}$ \\
\hline \multicolumn{6}{|l|}{$66-10$} \\
\hline \multirow[t]{4}{*}{$2.5(22.0 \pm 2.8)$} & $156.0(89.0 \pm 0.5)$ & $100.0 \pm 0.0(100,100)$ & $91.4(91.1,92.7)$ & $1.1^{\mathrm{g}}$ & $<0.0001$ \\
\hline & $78.0(51.5 \pm 1.8)$ & $83.2 \pm 6.2(67.7,98.7)$ & $62.2(60.9,63.5)$ & $1.3^{\mathrm{g}}$ & $<0.0001$ \\
\hline & $39.0(30.2 \pm 1.2)$ & $46.0 \pm 2.4(40.0,52.0)$ & $45.6(44.1,47.1)$ & 1.0 & 0.7417 \\
\hline & $19.5(16.5 \pm 2.7)$ & $37.0 \pm 1.7(32.8,41.3)$ & $34.9(32.8,37.0)$ & 1.1 & 0.2304 \\
\hline \multicolumn{6}{|l|}{$77-3$} \\
\hline \multirow[t]{4}{*}{$1.0(20.3 \pm 3.2)$} & $156.0(88.3 \pm 0.5)$ & $99.0 \pm 0.0(99.0,99.0)$ & $90.7(89.4,92.0)$ & $1.1^{\mathrm{g}}$ & $<0.0001$ \\
\hline & $78.0(50.3 \pm 2.1)$ & $77.7 \pm 2.9(70.5,85.0)$ & $60.4(58.9,61.9)$ & $1.3 \mathrm{~g}$ & $<0.0001$ \\
\hline & $39.0(27.0 \pm 0.0)$ & $51.7 \pm 2.5(45.5,58.0)$ & $41.8(40.2,43.4)$ & $1.2^{\mathrm{g}}$ & $<0.0001$ \\
\hline & $19.5(18.3 \pm 1.5)$ & $38.0 \pm 3.6(29.0,47.0)$ & $34.9(33.0,36.8)$ & 1.1 & 0.1273 \\
\hline \multicolumn{6}{|l|}{$77-12$} \\
\hline \multirow[t]{4}{*}{$0.75(7.7 \pm 2.3)$} & $156.0(91.3 \pm 1.5)$ & $98.3 \pm 0.6(96.8,99.8)$ & $92.0(91.0,93.0)$ & $1.1^{\mathrm{g}}$ & $<0.0001$ \\
\hline & $78.0(52.7 \pm 1.1)$ & $78.0 \pm 2.6(71.5,84.5)$ & $56.3(55.3,57.3)$ & $1.4^{\mathrm{g}}$ & $<0.0001$ \\
\hline & $39.0(34.6 \pm 0.6)$ & $47.3 \pm 1.5(43.5,51.1)$ & $39.7(38.6,40.8)$ & $1.2^{\mathrm{g}}$ & $<0.0001$ \\
\hline & $19.5(21.0 \pm 2.6)$ & $38.3 \pm 4.2(27.8,48.8)$ & $27.1(25.1,29.1)$ & 1.4 & 0.0002 \\
\hline
\end{tabular}

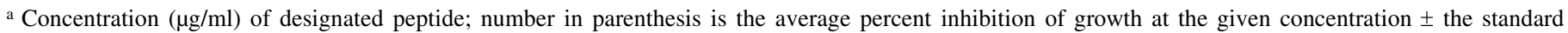
deviation (SD) for three independent experiments in triplicate.

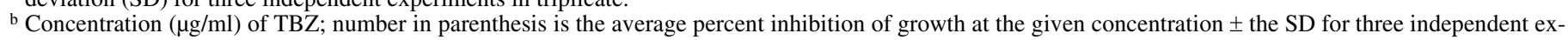
periments in triplicate.

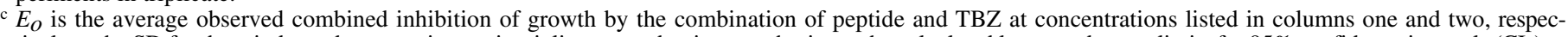
tively, \pm the SD for three independent experiments in triplicate; number in parenthesis are the calculated lower and upper limits for $95 \%$ confidence intervals (CIs).

${ }^{\mathrm{d}} E_{e}$ is the expected effect (percent inhibition) for an additive, non-synergistic effect; numbers in parenthesis are the calculated lower and upper limits for $95 \%$ CIs.

e $E_{o} / E_{e}>1$ and the $95 \%$ CIs for $E_{e}$ and $E_{o}$ do not overlap, then there is synergism.

f Calculated $P$ value.

$\mathrm{g}$ Synergistic interactions meeting both statistical criteria. 
tubes $(1.5 \mathrm{ml})$ were setup to contain $500 \mu \mathrm{l}$ of a $1 \times 10^{6}$ conidia per ml suspension and SYTOX Green. The peptide was then added to individual tubes, mixed, and allowed to incubate for 0, 5, 10,15 , and $30 \mathrm{~min}$ before being observed using fluorescence microscopy. The stained structures were photographed as previously described (34). Each incubation duration was performed in duplicate in three independent experiments with 100 conidia examined from each of three fields. The ratio of fluorescent to nonfluorescent conidia was used to determine the percent of membrane-compromised conidia present in the observed field. Controls consisted of mixtures containing either the peptide or the dye alone. To obtain compromised membranes under control conditions, the fungal structures were incubated in $70 \%$ ethanol for $10 \mathrm{~min}$ at $25^{\circ} \mathrm{C}$ (35), washed twice in PDB, and stained with dye. To determine the kill-time for $F$. sambucinum conidia using peptides $66-10$ or $77-3$, conidia $\left(5 \times 10^{4}\right)$ of strain R9260 were incubated with either peptide $66-10$ or $77-3$ at $10 \mu \mathrm{g} / \mathrm{ml}$ in a shaking waterbath at $25^{\circ} \mathrm{C}$. After incubation for $0,1,15,30$, or $60 \mathrm{~min}$, the tubes were removed from the waterbath and dilution plating was performed on potato dextrose agar. After $48 \mathrm{~h}$ at $25^{\circ} \mathrm{C}$, the number of colony forming units was determined. Each exposure duration and plating was performed in triplicate in three independent experiments and the data expressed as percent reduction in viability \pm standard deviation. The percent difference between the number of colony forming units for the peptide-treated conidia platings and the control (not treated) platings was used to calculate the percent kill for each incubation duration.

\section{RESULTS}

Determination of MIC's for fungal isolates. Radial growth of sensitive and resistant strains of $F$. sambucinum was similar after 5 days $(6.5 \pm 1.2 \mathrm{~mm}$ per day) on V8 juice agar. The sensitive strains did not grow on V8 juice agar amended with TBZ at $5 \mu \mathrm{g} / \mathrm{ml}$ (the lowest concentration tested). All the resistant strains grew well $(5.5 \pm 0.5 \mathrm{~mm}$ per day) at $50 \mu \mathrm{g} / \mathrm{ml}$, the highest concentration of TBZ tested in solid medium. To determine the range of concentrations of TBZ and peptides to be used in our studies it was first necessary to determine the MIC for both TBZ and peptides 66-10, 77-3, and 77-12 in broth culture. Approximately $4.8 \mu \mathrm{g} / \mathrm{ml}$ of TBZ was determined to be the MIC for the two sensitive strains tested (R9149 and R9262) (Table 1). A range of
172 to $312 \mu \mathrm{g} / \mathrm{ml}$ was required for complete inhibition of growth of the TBZ-resistant $F$. sambucinum strains. The MIC observed for peptide 66-10 for all strains ranged from 7.8 to $10.2 \mu \mathrm{g} / \mathrm{ml}$. The heptapeptide 77-3 showed an MIC that was approximately half or less than half that observed with 66-10 for all strains (Table 1). A wider range of MIC values was observed for peptide 77-12 when tested against the TBZ-sensitive and -resistant strains (Table 1).

Individual and synergistic activity. Peptides 66-10, 77-3, and 77-12 showed biocidal activity against TBZ-resistant $F$. sambucinum strains at low concentrations (Table 1). Therefore, it was of interest to determine if they could act in a synergistic manner with TBZ to inhibit the growth of TBZ-resistant strains of $F$. sambucinum.

Strain R9263 showed the highest resistance to TBZ (Table 1). A combination of peptide $66-10$ at $3.75 \mu \mathrm{g} / \mathrm{ml}$ and TBZ ranging from 19.5 to $78 \mu \mathrm{g} / \mathrm{ml}$ showed inhibitory activity that was between 1.5 and 2.2-fold greater than expected for additivity, indicating synergism (Table 2). Using a similar range of TBZ concentrations, the ratio of observed to expected inhibition $\left(E_{o} / E_{e}\right)$ values ranged from 1.4 to 2.2 and 1.6 to 2.6 , for peptides $77-3(2.0 \mu \mathrm{g} / \mathrm{ml})$ and $77-12$ $(1.5 \mu \mathrm{g} / \mathrm{ml})$, respectively (Table 2$)$. These data indicated that the peptides interacted synergistically with TBZ to inhibit growth of strain R9263. The synergy was most apparent at lower concentrations of the compounds. A twofold increase in the concentrations of each of the peptides, 66-10 $(7.5 \mu \mathrm{g} / \mathrm{ml}), 77-3(4.0 \mu \mathrm{g} / \mathrm{ml})$, or $77-$ $12(3.0 \mu \mathrm{g} / \mathrm{ml})$, showed growth inhibition of $89.3 \pm 3.0 \%, 98.0 \pm$ $0.0 \%$, and $63.0 \pm 3.0 \%$, respectively, that did not allow for evaluation of any synergistic activity. A twofold dilution of 66-10 $(1.88 \mu \mathrm{g} / \mathrm{ml})$ showed a $1.3 \pm 0.6 \%$ individual inhibitory effect with $E_{o}$ values of $69 \pm 1.0 \%, 43.7 \pm 5.0 \%$, and $17.0 \pm 2.0 \%$ in combination with TBZ at concentrations of 78,39 , and $19.5 \mu \mathrm{g} / \mathrm{ml}$, respectively, and respective $E_{o} / E_{e}$ values of 1.2, 2.0, and 2.0. The $E_{o} / E_{e}$ values indicate that synergism was also observed at lower peptide concentrations of 66-10, whereas twofold dilution of peptide $77-3(1.0 \mu \mathrm{g} / \mathrm{ml})$ or $77-12(0.75 \mu \mathrm{g} / \mathrm{ml})$ showed no individual inhibitory activity against strain R9263 precluding analysis for synergism. Therefore, using $78 \mu \mathrm{g} / \mathrm{ml}$ of TBZ (a fourfold reduction in the MIC of strain R9263) in combination with the peptides, an average of $97 \%$ growth inhibition was observed with the two heptapeptides, whereas, an $88.7 \%$ reduction was observed with peptide 66-10 (Table 2).

TABLE 4. Individual and synergistic activity of peptides and/or thiabendazole (TBZ) against TBZ-resistant Fusarium sambucinum strain R9257

\begin{tabular}{|c|c|c|c|c|c|}
\hline Peptide $^{a}$ & $\mathrm{TBZ}^{\mathrm{b}}$ & $E_{o}^{\mathrm{c}}$ & $E_{e}^{\mathrm{d}}$ & $E_{o} / E_{e}^{\mathrm{e}}$ & $P$ value $^{\mathrm{f}}$ \\
\hline \multicolumn{6}{|l|}{$66-10$} \\
\hline \multirow[t]{4}{*}{$4.5(36.0 \pm 1.7)$} & $156.0(79.7 \pm 3.0)$ & $98.7 \pm 0.6(97.2,100)$ & $87.0(85.7,88.3)$ & $1.1^{\mathrm{g}}$ & $<0.0001$ \\
\hline & $78.0(47.7 \pm 2.5)$ & $93.3 \pm 1.5(89.6,97.1)$ & $66.5(65.3,67.7)$ & $1.4^{\mathrm{g}}$ & $<0.0001$ \\
\hline & $39.0(21.0 \pm 2.6)$ & $73.7 \pm 1.2(70.7,76.7)$ & $49.4(47.9,50.9)$ & $1.5^{\mathrm{g}}$ & $<0.0001$ \\
\hline & $19.5(13.0 \pm 1.0)$ & $56.0 \pm 2.6(49.5,62.5)$ & $44.3(43.2,45.4)$ & $1.3^{\mathrm{g}}$ & $<0.0001$ \\
\hline \multicolumn{6}{|l|}{$77-3$} \\
\hline \multirow[t]{4}{*}{$1.0(16.3 \pm 0.6)$} & $156.0(80.0 \pm 1.7)$ & $99.0 \pm 0.0(99.0,99.0)$ & $83.3(82.3,84.3)$ & $1.2^{\mathrm{g}}$ & $<0.0001$ \\
\hline & $78.0(49.0 \pm 0.0)$ & $91.3 \pm 1.2(88.3,94.3)$ & $57.3(57.1,57.5)$ & $1.6^{\mathrm{g}}$ & 0.0003 \\
\hline & $39.0(23.7 \pm 2.1)$ & $53.3 \pm 1.2(50.3,56.3)$ & $36.1(34.9,37.3)$ & $1.5^{\mathrm{g}}$ & $<0.0001$ \\
\hline & $19.5(15.0 \pm 3.6)$ & $36.0 \pm 3.5(27.3,44.8)$ & $28.9(26.9,30.9)$ & 1.3 & 0.0514 \\
\hline \multicolumn{6}{|l|}{$77-12$} \\
\hline \multirow[t]{4}{*}{$2.0(19.0 \pm 2.0)$} & $156.0(92.7 \pm 0.6)$ & $100.0 \pm 0.0(100,100)$ & $94.1(93.8,94.4)$ & $1.1^{\mathrm{g}}$ & $<0.0001$ \\
\hline & $78.0(50.3 \pm 3.1)$ & $99.0 \pm 0.0(99.0,99.0)$ & $59.8(58.0,61.6)$ & $1.7^{\mathrm{g}}$ & $<0.0001$ \\
\hline & $39.0(25.7 \pm 3.8)$ & $88.0 \pm 4.6(76.5,99.5)$ & $39.8(37.5,42.1)$ & $2.2^{\mathrm{g}}$ & $<0.0001$ \\
\hline & $19.5(13.0 \pm 1.0)$ & $50.0 \pm 4.0(40.0,60.0)$ & $29.5(28.2,30.8)$ & $1.7^{\mathrm{g}}$ & $<0.0001$ \\
\hline
\end{tabular}

${ }^{a}$ Concentration $(\mu \mathrm{g} / \mathrm{ml})$ of designated peptide; number in parenthesis is the average percent inhibition of growth at the given concentration \pm the standard deviation (SD) for three independent experiments in triplicate.

${ }^{\mathrm{b}}$ Concentration $(\mu \mathrm{g} / \mathrm{ml})$ of TBZ; number in parenthesis is the average percent inhibition of growth at the given concentration \pm the SD for three independent experiments in triplicate.

${ }^{\mathrm{c}} E_{o}$ is the average observed combined inhibition of growth by the combination of peptide and TBZ at concentrations listed in columns one and two, respectively, \pm the SD for three independent experiments in triplicate; number in parenthesis are the calculated lower and upper limits for $95 \%$ confidence intervals (CIs).

${ }^{\mathrm{d}} E_{e}$ is the expected effect (percent inhibition) for an additive, non-synergistic effect; numbers in parenthesis are the calculated lower and upper limits for $95 \%$ CIs.

${ }^{\mathrm{e}} E_{o} / E_{e}>1$ and the $95 \%$ CIs for $E_{e}$ and $E_{o}$ do not overlap, then there is synergism.

f Calculated $P$ value.

g Synergistic interactions meeting both statistical criteria. 
For strain R9261, a combination of $66-10$ at $2.5 \mu \mathrm{g} / \mathrm{ml}$ (Table 3) with TBZ concentrations ranging from 19.5 to $156 \mu \mathrm{g} / \mathrm{ml}$ showed weak or no synergistic activity. Low synergistic activity was observed when the same series of TBZ concentrations were combined with peptide $77-3$ at $1.0 \mu \mathrm{g} / \mathrm{ml}$ (Table 3 ). Using a combination of $77-3$ at $2.0 \mu \mathrm{g} / \mathrm{ml}$ (individual inhibitory effect of $55.3 \pm$ $2.5 \%$ ) with $\mathrm{TBZ}$ at 78,39 , and $19.5 \mu \mathrm{g} / \mathrm{ml}, E_{o}$ values of $99.7 \pm$ $0.6 \%, 99.0 \pm 0.0 \%$, and $91.0 \pm 1.0 \%$ were obtained, respectively, and resulted in $E_{o} / E_{e}$ values of $1.3,1.5$, and 1.4, respectively. Despite the high $E_{e}$ and $E_{o}$ values observed, we detected synergistic interaction with TBZ. Peptide 77-12 showed some synergistic activity at $0.75 \mu \mathrm{g} / \mathrm{ml}$ in combination with TBZ (Table 3 ). When peptide 77-12 was present in a higher concentration $(1.5 \mu \mathrm{g} / \mathrm{ml}$; individual inhibitory effect of $44.7 \pm 4 \%)$ and was combined with TBZ at concentrations of 78, 39, and $19.5 \mu \mathrm{g} / \mathrm{ml}$, respectively, corresponding $E_{o} / E_{e}$ values of $1.3,1.5$, and 1.1 were obtained, with respective $E_{o}$ values of $98.3 \pm 0.6 \%, 93.3 \pm 3.2 \%$, and $60.7 \pm 0.6 \%$. The higher $E_{o}$ values are reflective of the increased individual inhibitory effect of $77-12$ at $1.5 \mu \mathrm{g} / \mathrm{ml}$. In general, synergistic activity for any of the peptide-TBZ combinations was lower for strain R9261 than that observed for the other strains.

Peptide $66-10$ at $4.5 \mu \mathrm{g} / \mathrm{ml}$ and $\mathrm{TBZ}$ at $39 \mu \mathrm{g} / \mathrm{ml}$ showed the best activity for the 66-10/TBZ series with strain R9257 (Table 4). A reduction of $66-10$ to $2.25 \mu \mathrm{g} / \mathrm{ml}$ (individual inhibitory effect of $8.0 \pm 1.0 \%$ ) resulted in reduced $E_{o}$ values of $54.7 \pm 2.5 \%, 35.7 \pm$ $4.1 \%$, and $25 \pm 2.5 \%$ when combined with $\mathrm{TBZ}$ at concentrations of 78,39 , and $19.5 \mu \mathrm{g} / \mathrm{ml}$, respectively and respective lower $E_{o} / E_{e}$ values of $1.1,1.3$, and 1.3 . Peptide $77-3$ at $1.0 \mu \mathrm{g} / \mathrm{ml}$ in combination with TBZ resulted in $E_{o} / E_{e}$ values of 1.2 to 1.6 (Table 4). At $2.0 \mu \mathrm{g} / \mathrm{ml} 77-3$ showed an individual inhibitory effect of $74.0 \pm$ $6.0 \%$, whereas at $0.5 \mu \mathrm{g} / \mathrm{ml}$ no activity was observed. The individual inhibitory effect values at both higher and lower peptide 77-3 concentrations were not optimal for assessment of potential synergistic activity. Peptide $77-12$ at $2.0 \mu \mathrm{g} / \mathrm{ml}$ showed the greatest overall synergistic activity of the peptides tested for isolate R9257, with $E_{o} / E_{e}$ values of between 1.1 and 2.2 when combined with the TBZ concentration dilution series (Table 4). Reduction of peptide $77-12$ to $1.0 \mu \mathrm{g} / \mathrm{ml}$ (individual inhibitory effect of $3.0 \pm$ $1 \%$ ) resulted in $E_{o}$ values of $76.7 \pm 5.5 \%, 46.7 \pm 4.0 \%$, and $17.3 \pm$ $1.5 \%$ and respective $E_{o} / E_{e}$ values of $1.5,1.7$, and 1.1 when combined with TBZ at concentrations of 78,39 , and $19.5 \mu \mathrm{g} / \mathrm{ml}$, re- spectively. Thus, as with strain R9263, synergy was readily detected with strain R9257.

The combination of peptide $66-10$ at $3.75 \mu \mathrm{g} / \mathrm{ml}$ with the twofold dilution series of TBZ using strain R9260 resulted in $E_{o} / E_{e}$ values between 1.1 and 1.4 (Table 5). Reduction of peptide $66-10$ to $1.88 \mu \mathrm{g} / \mathrm{ml}$ (individual inhibitory effects of $3.7 \pm 1.2 \%$ ) combined with TBZ at $78 \mu \mathrm{g} / \mathrm{ml}$ resulted in an $E_{o}$ value of $59.3 \pm$ $2.5 \%$ and an $E_{o} / E_{e}$ value of 1.2. Lower TBZ levels combined with the peptide at $1.88 \mu \mathrm{g} / \mathrm{ml}$ showed no synergistic activity. Peptide 77-3 showed good synergistic activity against strain R9260 with $E_{o} / E_{e}$ values ranging as high as 1.9 at $1 \mu \mathrm{g} / \mathrm{ml}$ of peptide (Table 5). Increasing the amount of peptide $77-3$ to $2.0 \mu \mathrm{g} / \mathrm{ml}$ (individual inhibitory effect of $48.3 \pm 3.2 \%$ ), however, reduced $E_{o} / E_{e}$ values to $1.4,1.5$, and 1.3 , respectively, as expected because of the high individual inhibitory effect but maintained respective $E_{o}$ values of $98.3 \pm 0.6 \%, 96 \pm 1.7 \%$, and $67.6 \pm 4 \%$ when combined with TBZ at concentrations of 78,39 , and $19.5 \mu \mathrm{g} / \mathrm{ml}$, respectively. The $E_{o} / E_{e}$ values for peptide 77-12 using the same twofold dilution series of TBZ ranged from 1.2 to 1.8 for strain R9260 (Table 5). Increasing peptide $77-12$ to $2.0 \mu \mathrm{g} / \mathrm{ml}$ (individual inhibitory effect of $32.0 \pm 1 \%$ ) resulted in $E_{o} / E_{e}$ values of $1.4,1.4$, and 1.6 , with respective $E_{o}$ values of $93.3 \pm 2.9 \%, 71.3 \pm 3 \%$, and $55.3 \pm 4.2 \%$, when combined with TBZ at concentrations of 78,39 , and $19.5 \mu \mathrm{g} / \mathrm{ml}$, respectively, indicating synergistic activity at the higher 77-12 concentration. Overall, the highest synergistic activity for strain R9260 across the range of TBZ concentrations tested was observed with peptide $77-3$ at $1.0 \mu \mathrm{g} / \mathrm{ml}$.

Mode of action. Fluorescence microscopy was used to determine the potential target site of heptapeptide 77-3 using strain R9260. Ethanol treated $F$. sambucinum conidia and mycelia, respectively, in the presence of membrane impermeant fluorescent dye, SYTOX Green, showed intact nuclei where the dye had complexed with the nucleic acids (Fig. 1A and C, respectively). Conidia and mycelia observed immediately after treatment with a mixture of SYTOX Green and peptide 77-3 showed that the impermeant dye had entered the peptide-treated conidia or mycelia and well-defined nuclei were no longer visible (Fig. 1B and D, respectively). In companion experiments, it was determined that cellular membranes were compromised and the nuclear membranes were also disrupted if the fungal structures were first incubated with 77-3 for $30 \mathrm{~min}$ and then stained or if the structures were incubated in the presence of a mixture of 77-3 and SYTOX

TABLE 5. Individual and synergistic activity of peptides and/or thiabendazole (TBZ) against TBZ-resistant Fusarium sambucinum strain R9260

\begin{tabular}{|c|c|c|c|c|c|}
\hline Peptide $^{\mathrm{a}}$ & $\mathrm{TBZ}^{\mathrm{b}}$ & $E_{o}{ }^{\mathrm{c}}$ & $E_{e}^{\mathrm{d}}$ & $E_{o} / E_{e}^{\mathrm{e}}$ & $P$ value ${ }^{f}$ \\
\hline \multicolumn{6}{|l|}{$66-10$} \\
\hline \multirow[t]{3}{*}{$3.75(22.0 \pm 0.0)$} & $156.0(83.3 \pm 1.1)$ & $97.3 \pm 1.2(94.3,100)$ & $87.0(86.4,87.6)$ & $1.1^{\mathrm{g}}$ & $<0.0001$ \\
\hline & $78.0(47.7 \pm 2.9)$ & $82.3 \pm 0.6(80.8,83.8)$ & $59.2(57.7,60.7)$ & $1.4^{\mathrm{g}}$ & $<0.0001$ \\
\hline & $19.5(13.3 \pm 2.1)$ & $44.0 \pm 1.0(41.5,46.5)$ & $32.4(31.3,33.5)$ & $1.4^{\mathrm{g}}$ & $<0.0001$ \\
\hline \multicolumn{6}{|c|}{ 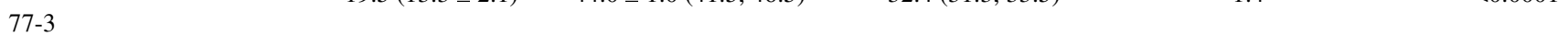 } \\
\hline \multirow[t]{2}{*}{$1.0(11.7 \pm 1.5)$} & $156.0(81.0 \pm 3.0)$ & $98.0 \pm 0.0(98.0,98.0)$ & $83.2(81.4,85.0)$ & $1.2^{\mathrm{g}}$ & $<0.0001$ \\
\hline & $78.0(47.3 \pm 1.5)$ & $78.3 \pm 3.2(70.3,86.3)$ & $53.5(52.5,54.5)$ & $1.5^{\mathrm{g}}$ & $<0.0001$ \\
\hline \multicolumn{6}{|l|}{$77-12$} \\
\hline \multirow[t]{4}{*}{$1.0(8.0 \pm 1.0)$} & $156.0(79.3 \pm 4.7)$ & $95.3 \pm 0.6(93.8,96.8)$ & $81.0(78.1,83.9)$ & $1.2^{\mathrm{g}}$ & $<0.0001$ \\
\hline & $78.0(50.0 \pm 3.5)$ & $70.0 \pm 3.6(61.0,79.0)$ & $54.3(52.1,56.5)$ & $1.3^{\mathrm{g}}$ & $<0.0001$ \\
\hline & $39.0(26.0 \pm 4.3)$ & $54.0 \pm 2.6(47.5,60.5)$ & $31.9(29.2,34.6)$ & $1.7^{\mathrm{g}}$ & $<0.0001$ \\
\hline & $19.5(5.0 \pm 1.0)$ & $22.7 \pm 3.8(13.2,32.2)$ & $12.6(11.7,13.5)$ & 1.8 & 0.0405 \\
\hline
\end{tabular}

$\bar{a}$ Concentration $(\mu \mathrm{g} / \mathrm{ml})$ of designated peptide; number in parenthesis is the average percent inhibition of growth at the given concentration \pm the standard deviation (SD) for three independent experiments in triplicate.

${ }^{\mathrm{b}}$ Concentration $(\mu \mathrm{g} / \mathrm{ml})$ of TBZ; number in parenthesis is the average percent inhibition of growth at the given concentration \pm the SD for three independent experiments in triplicate.

${ }^{\mathrm{c}} E_{o}$ is the average observed combined inhibition of growth by the combination of peptide and TBZ at concentrations listed in columns one and two, respectively, \pm the SD for three independent experiments in triplicate; number in parenthesis are the calculated lower and upper limits for 95\% confidence intervals (CIs).

${ }^{\mathrm{d}} E_{e}$ is the expected effect (percent inhibition) for an additive, non-synergistic effect; numbers in parenthesis are the calculated lower and upper limits for 95\% CIs.

${ }^{\mathrm{e}} E_{o} / E_{e}>1$ and the $95 \%$ CIs for $E_{e}$ and $E_{o}$ do not overlap, then there is synergism.

${ }^{\mathrm{f}}$ Calculated $P$ value.

g Synergistic interactions meeting both statistical criteria. 
Green (data not shown). Fungal structures were also treated with ethanol, washed, incubated with the peptide for $30 \mathrm{~min}$, and stained with SYTOX Green or stained with dye and incubated for $30 \mathrm{~min}$. In each treatment, the impermeant dye entered the structure through the ethanol treated (compromised) cytoplasmic membrane and stained the nuclei with identical microscopic results to those depicted in Figures 1A and 1C. Untreated conidia or mycelia in the presence of only SYTOX Green showed no fluorescence (data not shown). Incubation of strain R9260 conidia with $77-3(10 \mu \mathrm{g} / \mathrm{ml})$, SYTOX Green showed that $78 \pm 2.6 \%$ of the treated conidia showed compromised membranes within 5 min. By 15 min, $99 \pm 1.0 \%$ of the conidia showed confluent fluorescent staining and had lost a defined internal nuclear structure indicating that a majority of the nuclei had been compromised.

A 1 to 2 min exposure of condia resulted in a $24 \pm 3.6 \%$ reduction in viability with $66-10$, whereas, with $77-3$ a $53 \pm 5.0 \%$ reduction was observed. A 15,30 and 60 min exposure to 66-10 resulted in $45 \pm 5.0 \%, 62 \pm 6.1 \%$, and $90 \pm 3.0 \%$ reduction in viability, respectively, whereas a $91 \pm 3.6 \%, 98 \pm 2.6 \%$, and $100 \pm$ $0.0 \%$ reduction in viability, respectively, was observed using 77-3 and the same exposure times. Hence, conidia appeared to be more sensitive to peptide 77-3 than to 66-10.

\section{DISCUSSION}

We have previously shown that the peptide hexamer 66-10 exhibits activity against Fusarium oxysporum f. sp. lycopersici, Rhizoctonia solani (anastomosis group I), Ceratocystis fagacearum, and Pythium ultimum (34). In this study, we have shown that peptide 66-10 also has activity against TBZ-sensitive and -resistant strains of $F$. sambucinum (average MIC of $9.5 \mu \mathrm{g} / \mathrm{ml} \pm 0.8$; $11.2 \mu \mathrm{M})$. An extension of the hexapeptide 66-10 with the hydrophobic nonpolar amino acids phenylalanine or isoleucine resulted in peptides 77-3 and 77-12, respectively. The two heptapeptides were selected because of their high biocidal activity to several genera of plant pathogenic fungi (data not shown). Heptapeptides 77-3 and 77-12 showed increased activity over 66-10 against the F. sambucinum strains evaluated, with an average MIC for all strains tested of $3.9 \mu \mathrm{g} / \mathrm{ml} \pm 0.1(3.9 \mu \mathrm{M})$ and $5.5 \mu \mathrm{g} / \mathrm{ml} \pm 1.9$ $(5.2 \mu \mathrm{M})$, respectively. The lower average MIC of 77-3, as compared with 77-12, may be a reflection of the greater hydrophobicity of phenylalanine as compared to isoleucine resulting in increased hydrophobic interaction with cell membranes.

The D-amino acid peptides 66-10 (FRLKFH-NH ${ }_{2}$, 77-3 (FRLKFHF- $\mathrm{NH}_{2}$ ), and 77-12 (FRLKFHI-NH ${ }_{2}$ ), are small, cationic peptides with hydrophobic backbones. The biological activity of amphipathic $\alpha$-helical peptides is thought to result from their ability to form ion channels through membrane bilayers $(6,27)$ and a length of at least 20 amino acid residues is usually necessary to completely span the hydrocarbon portion of the lipid bilayer (27). With a length of 6 to 7 amino acids, the observed biological activity cannot be attributed to the membrane spanning action of peptide monomers. However, Anzai et al. (6) have shown that short cationic peptides ( 8 to 12 amino acids long) are able to form ion channels. Reed et al. (34) have previously shown the ability of peptide 66-10 to compromise biological membranes and, as others $(2,6)$, proposed that oligomeric bundles of head-to-tail dimers of short peptides are a potential explanation for its activity. The cationic nature of the three peptides used in the study is conferred by the presence of positively charged amino acids arginine, lysine, and/or histidine and is further enhanced by the separation of the positive charges by the hydrophobic residues phenylalanine and leucine. The cationic, hydrophobic attributes observed in the developed peptides is one that is prevalent in naturally occurring antimicrobial peptides $(2,7,8,16)$. This structure enhances the capabilities of the charged residues to interact with the hydropho-
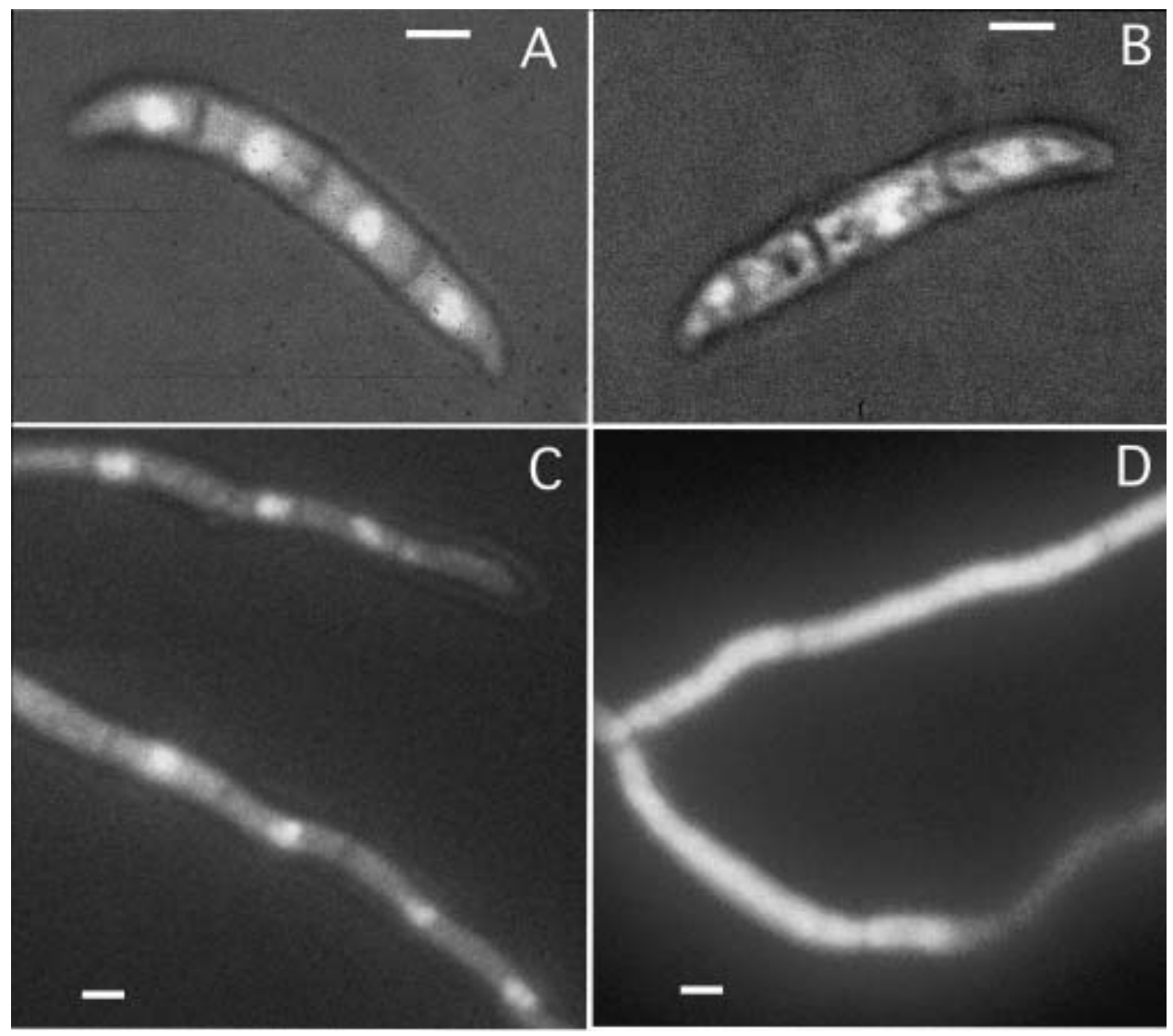

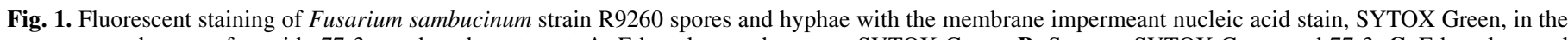

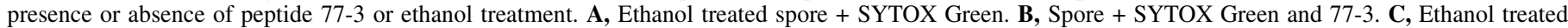
mycelial + SYTOX Green. D, Mycelial + SYTOX Green and 77-3. Bars represent $5 \mu \mathrm{m}$. 
bic chains of the negatively charged phospholipids of the cell membranes and may explain the observed compromised membranes.

Characterization of 66-10 has also shown that it has no hemolytic or mutagenic activity (34). Studies using the same protocol (data not shown) have confirmed that both 77-3 and 77-12 show no hemolytic activity at concentrations up to $16 \mu \mathrm{g} / \mathrm{ml}$; with $77-3$ and 77-12 showing 3 and 9\% lysis of human red blood cells, respectively, at $32 \mu \mathrm{g} / \mathrm{ml}$ which may reflect their more hydrophobic nature relative to 66-10. The fact that the peptide 66-10 and its derivatives show high biocidal activity against the $F$. sambucinum strains and no hemolytic activity at fungicidal concentrations suggests that they may have greater activity to compromise fungal rather that human erythrocyte membranes and therefore warrant further development as antifungal agents.

A comparison of the calculated MIC values for the TBZ- sensitive verses TBZ-resistant strains of $F$. sambucinum indicates a range in the MIC values that are 37-fold to 62-fold higher than that observed for the sensitive strains. Thiabendazole, a benzimidazole, is a specific inhibitor of microtubule assembly that acts by binding to tubulin (10) and the binding affinity of benzdimidazoles to tubulin in vitro correlates with the sensitivity of strains to the fungicide (11). In naturally occurring benomyl-resistant Botrytis cinerea, Yarden and Katan (37) correlated mutations leading to substitutions at amino acids 198 and 200 of beta-tubulin with various benomyl-resistant phenotypes. A glutamic acid to lysine or alanine substitution at amino acid 198 was correlated with a high resistance, whereas a phenylalanine to tyrosine substitution at amino acid 200 was correlated with moderate resistance. Mutations leading to substitutions in the amino acid sequence of beta-tubulin have also resulted in altered sensitivity to thiabendazole and other benzimidazole drugs in yeast, Neurospora crassa, Aspergillus nidulans, and Trichoderma viride (18,20,23,24,32,36). At this time, we can only speculate that the differences in TBZ resistance observed in F. sambucinum strains are due to such allelic mutations. Indeed, genetic analysis of TBZ-resistant $F$. sambucinum has indicated that TBZ resistance is stable and inherited as a single locus and that resistance mutations of independent isolates are allelic (14).

Antimicrobial combinations are most frequently used to provide broad-spectrum coverage and in some instances are used because an identified pathogen is resistant to inhibition by conventional doses of a single antimicrobial agent that is normally effective (15). In either case the interaction may depend on the effects of the antimicrobial combinations against the individual pathogen. Synergistic activity also often allows for a reduction in the effective doses of antimicrobial compounds (15). Milewski et al. (29) have stated that there are three generally accepted mechanisms of synergistic activity; increase by one agent of the permeability of the cell wall and membranes to the second agent; inhibition of the ability to degrade the second agent; and double blocking by the two components of successive steps in a metabolic sequence. The antifungal activity of peptide 66-10 has been previously demonstrated $(3,28,34)$. In this study, we have shown not only the biocidal activity of 66-10 and its derivatives 77-3 and 77-12 against TBZ-resistant strains of $F$. sambucinum, but also that the developed peptides can act synergistically with TBZ. Synergism was observed for all strains tested with the combination of each of the three peptides and TBZ. However, there appear to be two classes of strain response for TBZ-resistant strains. One class includes strains R9363, R9257, and R9260 in which strong synergism is indicated by the high $E_{o} / E_{e}$ values. In contrast, the combination of the compounds displayed weak synergistic activity against strain R9261. This may reflect differences in the mode of resistance alleles at a single locus such as that observed with $B$. cinerea (37). Given that TBZ interacts with tubulin and that the peptides affect membrane integrity, the observed synergistic activity may be related to a disruption of required cross-talk between actin filaments, microtubles, and proteins anchored to the plasma membrane. This cross-talk is essential for a number of cellular functions, such as intracellular transport and polar growth $(4,25)$. Therefore, microtubule function may represent a direct target of TBZ (10) and is a likely indirect target of peptide action on membranes. Alternatively, TBZ-resistance could involve the action efflux pumps. Two major groups of transporters, the ATP-binding-cassette (ABC) and the major facilitator superfamily (MFS) transporters have been found to play major roles in fungicide sensitivity and resistance $(5,12)$. Disruption of efflux pump activity by the membrane active peptides could result in the synergistic activity observed between the TBZ and the peptides. If indeed the membrane disruptive activity of the peptides affects either ABC or MFS transporters involved in fungicide resistance, it is possible that the peptides could act synergistically with a wide variety of compounds for which resistance by efflux transporters has been observed. The data from this study indicate that cationic peptides can be fungicidal at low concentrations ( 4 to $8 \mu \mathrm{M})$ and show potential to act against fungicide-resistant pathogens individually and in a synergistic manner at low concentrations $(0.8$ to $3 \mu \mathrm{M})$. The synthetic peptides designed in this study can be used as a basis for further development to improve factors such as specificity and toxicity. The D-amino acid composition of the peptides makes them more resistant to proteolysis and therefore more stable in vivo. The positive interaction demonstrated by several of the combinations indicates that the peptides have potential use to enhance the activity of other fungicides currently in use for the control of pathogens.

\section{ACKNOWLEDGMENTS}

This research was supported by NCE Pharmaceuticals. We thank J. L. Starr for his critical reading of the manuscript.

\section{LITERATURE CITED}

1. Abbott, W. S. 1925. A method of computing effectiveness of an insecticide. J. Econ. Entomol. 18:265-267.

2. Agawa, Y., Lee, S., Ono, S., Aoyagi, H., Ohno, M., Taniguchi, T., Anzai, K., and Kirino, Y. 1991. Interaction with phospholipid bilayers, ion channel formation, and antimicrobial activity of basic amphipathic $\alpha$ helical model peptides of various chain lengths. J. Biol. Chem. 266: 20218-20222.

3. Ali, G. S., and Reddy, A. S. N. 2000. Inhibition of fungal and bacterial plant pathogens by synthetic peptides: In vitro growth inhibition, interaction between peptides and inhibition of disease progression. Mol. PlantMicrobe Interact. 13:847-859.

4. Allan, V., and Nathke, I. S. 2001. Catch and pull a microtubule: Getting a grasp on the cortex. Nature Cell Biol. 3:E226-E228.

5. Andrade, A. C., Del Sorbo, G., Van Nistelrooy, J. G. M., and De Waard, M. A. 2000. The ABC transporter AtrB from Aspergillus nidulans mediates resistance to all major classes of fungicides and some natural toxic compounds. Microbiology 146:1987-1997.

6. Anzai, K., Hamasuna, M., Kadono, H., Lee, S., Aoyagi, H., and Kirino, Y. 1991. Formation of ion channels in planer lipid bilayer membranes by synthetic basic peptides. Biochim. Biophys. Acta. 1064:256-266.

7. Bessalle, R., Kapitkovsky, A., Gorea, A., Shalit, I., and Fridkin, M. 1990. All D-magainins: Chirality, antimicrobial activity, and proteolytic resistance. FEBS. 274:151-155.

8. Blondelle, S. E., and Houghten, R. A. 1992. Design of model amphipathic peptides having potent antimicrobial activities. Biochemistry 31: 12688-12694.

9. Blondelle, S. E., and Lohner, K. 2000. Combinatorial libraries: A tool to design antimicrobial and antifungal peptide analogues having lytic specificities for structure-activity relationship studies. Biopolymers 55:7487 .

10. Davidse, L. C. 1986. Benzimiadole fungicides: Mechanism of action and biological impact. Annu. Rev. Phytopathol. 24:24:43-65.

11. Davidse, L. C., and Flach, W. 1977. Differential binding of methylbendzimidazole-2-yl carbamate to fungal tublin as a mechanism of resistance to this antimitotic agent in mutant strains of Aspergillus nidulans. J. Cell Biol. 72:174-193.

12. Del Sorbo, G., Schoonbeck, H., and De Waard, M. A. 2000. Fungal transporters involved in efflux of natural toxic compounds and fungicides. Fungal Genet. Biol. 30:1-15. 
13. Desjardins, A. E. 1995. Population structure of Gibberella pulicaris (Anamorph Fusarium sambucinum) from potato tuber dry rot in North America and Europe. Am. Potato J. 72:145-156.

14. Desjardins, A. E., Christ-Harned, E. A., McCormick, S. P., and Secor, G. A. 1993. Population structure and genetic analysis of field resistance to thiabendazole in Gibberella pulicaris from potato tubers. Phytopathology 83:164-170.

15. Eliopoulos, G. M., and Moellering, R. C., Jr. 1996. Antimicrobial combinations. Pages 330-396 in: Antibiotics in Laboratory Medicine. V. Lorian, ed. The Williams and Wilkins Co., Baltimore, MD.

16. Evans, E. W., and Harmon, B. G. 1995. A review of antimicrobial peptides: Defensins and related cationic peptides. Vet. Clin. Pathol. 24:109116.

17. Fisher, N. L., Burgess, L. W., Toussoun, T. A., and Nelson, P. E. 1982. Carnation leaves as a substrate and for preserving cultures of Fusarium species. Phytopathology 72:151-153.

18. Fugimura, M., Oeda, K., Inoue, H., and Kato, T. 1992. A single aminoacid substitution in the beta-tubulin gene of Neurospora confers both cabendazim resistance and diethofencarb sensitivity. Curr. Genet. 21: 399-404.

19. Gisi, U. 1996. Synergistic interaction of fungicides in mixtures. Phytopathology 86:1273-1279.

20. Goldman, G. H., Temmerman, W., Jacobs, D., Contreras, R., Van Montagu, M., and Herrera-Estrella, A. 1993. A nucleotide substitution in one of the $\beta$-tubulin genes of Trichoderma viride confers resistance to the antimitotic drug methyl benzimidazole-2-yl-carbamate. Mol. Gen. Genet. 240:73-80.

21. Hanson, L. E., Schwager, S. J., Loria, R. 1996. Sensitivity to thiabendazole in Fusarium species associated with dry rot of potato. Phytopathology 86:378-384.

22. Holley, J. D., and Kawchuk, L. M. 1996. Distribution of thiabendazole and thiophanate-methyl resistant strains of Helminthosporium solani and Fusarium sambucinum in Alberta potato storages. Can. Plant Dis. Surv. 76:21-27.

23. Jung, M. K., and Oakley, B. R. 1990. Identification of an amino acid substitution in the benA, $\beta$-tubulin gene of Aspergillus nidulans that confers thiabendazole resistance and benomyl supersensitivity. Cell Motil. Cytoskelet. 17:87-94.

24. Jung, M. K., Wilder, I. B., and Oakley, B. R. 1992. Amino acid alterations in the benA ( $\beta$-tubulin) gene of Aspergillus nidulans that confer benomyl resistance. Cell Motil. Cytoskelet. 22:170-174.

25. Karki, S., and Holzbaur, E. L. F. 1999. Cytoplasmic dynein and dynactin in cell division and intracelluar transport. Curr. Opin. Cell Biol. 11:4553.

26. Leach, S. S., and Nielsen, L. W. 1975. Elimination of fusarial contamination on seed potato. Am. Potato J. 52:211-218.

27. Lear, J. P., Wasserman, Z. R., and Degrado, W. F. 1988. Synthetic, amphiphilic peptide models for protein ion channels. Science $246: 1177-$ 1181.

28. Lopez-Garcia, B., Gonzalez-Candelas, L., Perez-Paya, E., and Marcos, J. F. 2000. Identification and characterization of a hexapeptide with activity against phytopathogenic fungi that cause postharvest decay in fruits. Mol. Plant-Microbe Interact. 13:837-846.

29. Milewski, S., Mignini, F., and Borowski, E. 1991. Synergistic action of nikkomycin $\mathrm{X} / \mathrm{Z}$ with azole antifungals on Candida albicans. J. Gen. Microbiol. 137:2155-2166.

30. O'Brien, M. J., and Rich, A. E. 1976. Potato diseases. Pages 22-24 in: Agricultural Handbook 474. USDA- ARS, Washington, D.C.

31. Olsen, R. H., and Hansen, J. 1976. Evolution and utility of a Pseudomonas aeruginosa drug resistance factor. J. Bacteriol. 125:837-844.

32. Orbach, M. J., Porro, E. B., and Yanofsky, C. 1986. Cloning and characterization of the gene for $\beta$-tubulin from a benomyl-resistant mutant of Neurospora crassa and its use as a dominant selectable marker. Mol. Cell Biol. 6:2452-2461.

33. Pagano, M., and Gauvreau, K. 2000. Principles of Biostatistics. 2nd ed. Duxbury Thomson Learning. Pacific Grove, CA.

34. Reed, J. D., Edwards, D. L., and Gonzalez, C. F. 1997. Synthetic peptide combinatorial libraries: A method for the identification of bioactive peptides against phytopathogenic fungi. Mol. Plant-Microbe Interact. 10: 537-549.

35. Springer, M. L., and Yanofsky, C. 1989. A morphological and genetic analysis of conidiophore development in Neurospora crassa. Genes Dev. 3:559-571.

36. Thomas, J. H., Neff, N. F., and Botstein, D. 1985. Isolation and characterization of mutations in the $\beta$-tubulin gene of Saccharomyces cerevisiae. Genetics 112:715-734.

37. Yarden, O., and Katan, T. 1993. Mutations leading to substitutions at amino acids 198 and 200 of beta-tubulin that correlate with bemomyl-resistance phenotypes of field strains of Botrytis cinerea. Phytopathology $83: 1478-1483$ 